\title{
SISTEMA DE CIDADES, FUNDAMENTO DE ORGANIZAÇÃO TERRITORIAL? análise comparada entre Brasil e Estados Unidos*
}

\author{
Cynthia Ghorra-Gobin \\ CNRS/Credal - France \\ implementation@orange.fr
}

Hervé Théry

Resumo

O presente artigo intenta, a partir da consideração do processo dialético entre território nacional e cidades no tempo (do período colonial à meados do século $\mathrm{XX}$ ), estabelecer uma análise comparativa entre Brasil e Estados Unidos. Parte-se, para tanto, de um conjunto de questionamentos. A organização do território provêm da cidade ou, ao contrário, a fundação da cidade se dá a partir da instauração de um poder político a se afirmar na construção do território? É a cidade ou o território que se apresentam como parâmetro fundamental na formação do Estado? A gênese do território nacional desenha o sistema urbano, ou o contrário? Se propondo a responder tais questionamentos, a análise comparativa apresentada, confirma o papel preponderante do Estado na dinâmica urbana, inscrevendo-se como um jogo político no qual os Estados federais participam. Grosso modo, esta dinâmica dual explica a estabilidade econômica e política dos dois países.

hthery@aol.com

\section{Abstract}

This article aims to conduct a comparative analysis between Brazil and the United States focused on the nacional territory and the cities in the course of their respective histories, from the colonial period to the mid-twentieth century. It proposes to explain the dialectic between the two phenomena. The organization of the territory comes from the city or on the contrary, the foundation of the city comes from the establishment of a political power that asserts itself through the construction of the territory? Which one, the city or the territory is presented as the basic parameter to the formation of the State? The genesis of the national territory draws the urban system, or the contrary? The comparative analysis aims to answer these questions and thus confirm the inavitable role of the state in the urban dynamics while political game and where federal states are present. This duality explains the stability of the economic and political dynamics of the two countries.

Palavras-chave: Análise comparativa, Brasil, Estados Unidos da América, organização do território, cidade.

Key Words: Analysis between, Brazil, United States, organization of the territory, city.

\section{INTRODUÇÃO}

A análise comparativa é pouco frequente tanto na geografia como nas ciências sociais. Comumente a consideram sem valor heurístico e limitada a estabelecer paralelo entre estudos de caso relacionados a áreas culturais distintas. Na maioria das vezes se restringe a destacar semelhanças e diferenças e, nestes termos, a confirmar ou refutar uma tese sem contribuir em discussão genuínamente científica. Dentre a teses em voga as de que: as cidades contribuem para a riqueza nacional, os excluídos do mercado de trabalho nas metrópoles dos países ricos são vítimados pela desindustrialização, o crescimento urbano resulta da pressão dos promotores sobre os políticos. No entanto, o contexto atual, fundado em nova etapa do capitalismo, a da globalização, suscita intensificação das trocas comerciais (em domínios também

(*) Tradução do original, "Le système de villes, fondement de l'organisation territoriale ? Analyse comparée du Brésil et des ÉtatsUnis”. In: Archicube (2008), realizada por Eustogio Wanderley Correia Dantas e Raimundo Freitas Aragão. 
diversificados como a informação, a produção artística, as crenças religiosas, etc.) e reposicionamento (econômico e político) de países em escala global, dado a impor consideração das contribuições da abordagem comparativa.

No alvorecer do século XXI, definido por cientistas políticos como era pós-americana (post-American world), período no qual as posições políticas e econômicas nas Américas se redefinem paralelamente ao advento dos países emergentes e de um poder emergente, em uma análise comparativa entre os Estados Unidos (potência que marcou profundamente o século XX) e o Brasil (potência emergente) se torna pertinente trabalhar a relação cidade e território. A entrada do "território" no "Dictionnaire des Mondialisations" (COLIN, 2006) propõe dinâmica do tipo desterritorialização-reterritorialização, enquanto a entrada de "cidade" propõe destinguir três categorias: cidade global, cidade mundial e capital internacional. A primeira corresponde a uma entidade urbana bem estabelecida nas redes globais e a assegurar um papel dominante no comando da economia mundial. A segunda se destingue da primeira por sua atratividade cultural, patrimônio cultural ou ainda, pela influência cultural, não se traduzindo em sua capacidade econômica. A capital internacional, embora não seja uma categoria nova, posto ser intrínseca ao próprio conceito de Estado, passa por reposicionamento com o advento das demais categorias. Países como Brasil e Estados Unidos são exemplos de realidades interessantes a estudar por, no decurso de suas histórias políticas, optarem em desassociar os conceitos de cidades econômicas e culturais daquele de capital política. No Brasil, Brasília, São Paulo e Rio de Janeiro, são, respectivamente, capital internacional, cidade global e cidade mundial. Nos Estados Unidos, Washington DC é capital internacional, Nova York representa ainda a forma de centralidade econômica e Los Angeles que figurava como cidade mundial tanto por seu peso econômico como por sua influência na indústria cinematrográfica, entrou no clube das cidades globais, mas não é como anteriormente a capital mundial do cinema e partilha esse título com Munbai.

A análise ora empreendida se pauta em duas fases históricaas geralmente estabelecidas pela historiografia dos dois países:

1- A fase colonial 1492-1806/1822: Para os Estados Unidos, ela finda, a priori, em 1776 (no momento da guerra da independência), mas necessário aguardar início do século XIX para acontecer a desintegração dos impérios coloniais no Novo Mundo, incluso a declaração de independência do Brasil em 1822.

2- A emergência dos Estados-Nações pautada na apropriação territorial: até metade do século XX, antes do advento da atual globalização, dividido em dois sub períodos: 1806/1822-1888 - traduzida para os Estados Unidos e o Brasil em conquista espacial continental, e mesmo transcontinental no primeiro caso, ao objetivar abertura para o pacífico; 1888-1960 - articulação entre o sistema federal e de cidades:.

\section{O PERÍODO COLONIAL 1492-1806 / 1822}

O período colonial inicia com primeiro advento de mundialização moderna, fundada nos reinos europeus. Se geralmente a data de 1492 é atribuída à da descoberta do Novo Mundo pelo genovês Cristóvão Colombo, à serviço da Coroa Espanhola, a data de 1497 e o personagem John Cabot (veneziano a serviço da Coroa Inglesa) são, provavelmente, mais adequados à colonização britânica. A análise dessa fase histórica, voltada principalmente à costa atlântica dos dois países, se dá pautada na análise da: a) utilização dos termos para qualificar as cidades e estabelecimentos humanos e b) ausência de qualquer sistema de cidades e de centralidade localizada ainda no universo atlântico, em rede de trocas comerciais com a Europa e a África. 


\section{Tipos de cidades}

$\mathrm{Na}$ América inglesa, as noções de colônias e de plantações se inscrevem no linguajar corrente dos meados do século XIX. A colonização se baseia na criação de assentamentos (settlements) e postos avançados (outpost), alguns grupamentos humanos se fixando mais nos primeiros do que nos últimos. Nesta época, a utilização do plano em tabuleiro consiste em exceção à regra (Filadélfia, Pensilvânia e de New Haven, Connecticut).

. Settlement, estabelecimento humano, a fazer referência a uma certa densidade populacional sem indicar funções rurais ou mercantis: os assentamentos são compostos, muitas vezes, na articulação destas duas funções.

. outposts, termo próximo de « feitorias » enfatiza a função de trocas transatlânticas, principalmente, com as cidades: os outposts de maior destaque são geralmente os seaposts (postos marítimos).

. Town, associado à colonização da comunidade puritana em Boston e seus arredores.

As cidades são igualmente feitorias na América portuguesa, tendo como função principal centralizar as trocas transatlânticas, unicamente com as cidades portuguesas posto o regime de exclusividade colonial fechar os portos da colônia aos navios de outras nações, e reservava o monopólio do comércio aos portos e navios portugueses. Existem dois tipos de cidades:

- a cidade é uma vila em pleno exercício, sendo reconhecida como tal pela Coroa, e

. as vilas, que não foram ou ainda serão elevadas ao estato de cidade. Frequentemente se caracterizam como « boca do sertão », ponto de acesso às zonas ainda não ocupadas, o sertão grosso modo apresentado como sinônimo de wilderness norte americano ou de outback australiano.

Nota-se uma grande diferença em relação ao sistema espanhol, mais rígido e no qual as cidades são criadas - e deslocadas caso fracassem - com a permissão do rei, como demonstra Alain Musset (2002). Até mesmoo planta das cidades é diferente, opondo-se o quadrangular das cidades espanholas e à amável desordem das cidades portuguesas, uma oposição resumida pelo historiador brasileiro Sérgio Buarque de Holanda como formula imagética do «telhado» espanhol, a estabelecer uma rigorosa grade de cidades e do « semeador » português a lançar aparentemente as suas aos ventos (ao acaso).

\section{As cidades : um arquipélago de lugares}

A fachada atlântica da América do Norte qualificada como « patchwork », por ser composta de territórios facilmente identificáveis na paisagem em razão da concentração de europeus a compartilhar algumas práticas sociais, culturas e econômicas. Neste « patchwork territorial » (MEINIG, 1986, 1993, 1998), cada um dos territórios delimitados geralmente por fronteiras naturais (rio, riacho, colina ou montanha) dispõe de certa homogeneidade etno-linguistica, fundada seja no uso de uma língua em particular (francês, holandês, espanhol, inglês, português), seja na filiação religiosa. Difícil remeter aos fluxos migratórios de franceses, de britânicos, sem considerar suas proveniências de uma região específica.

No entanto, estes diferentes territórios, a se organizarem do ponto de vista político, participam da origem destas 13 colônias. Os últimos incluem o território da Pensilvânia que compreende a Fildélfia, a cidade mais importante da fachada atlântica. Neste contexto territorial sem integração, mas não desorganizado, as cidades são vistas como lugares facilitadores e organizadores da colonização dos territórios.

Revista da ANPEGE. v. 6, 2010 (jan./dez.) 
Constituem «mosaico » de lugares cujas relações com as cidades européias são mais intensas do que a notada entre elas. Nos meados do século XVIII, a centralidade desta nação em efevercência se pautava em um sistema bipolar composto por Filadélfia e Nova York. Durante longo período de tempo, a primeira cidade foi a mais importante, tanto por seu peso demográfico como por sua influência cultural e política. A segunda se afirma como cidade portuária voltada para o mundo atlântico e não somente aos Estados Unidos. Os habitantes da colônia de Virgínia foram certamente os mais atuantes na construção do Estado federal e da nação americana. Este engajamento político explica, sobremaneira, a escolha da localização da capital nacional às margens do Potomac e em detrimento das duas outras cidades, que, entretanto, dispunham de forte vitalidade econômica. Nestes termos, a dimensão política da capital se diferencia da dinâmica econômica.

No Brasil as cidades são pontos voltados à exportação, a riqueza e o poder se encontram no campo, nas grandes plantações, onde residem os proprietários de terras. O sistema urbano - se é que merece esse nome - é um arquipélago de ilhas (as cidades portuárias sobre as quais estão centralizadas as células exportadoras) a se comunicarem entre si por cabotagem, e, às vezes, com maior facilidade com Lisboa.

Cada « ilha » do arquipélago é resultado do loteamento da fachada atlântica pela Coroa em capitanias hereditárias, cujos beneficiários são responsabilizados por seu desenvolvimento, sob uma única base de produção (cana-de-açucar, pau brasil, tabaco) e de composição étnica, com exceção de São Paulo, nascida de um colégio jesuíta e especializada na caça de escravos e exploração do interior. A partir desta minúscula cidade (no começo do século XIX ela contava com 10.000 habitantes) partiram as expedições basilares na expansão do domínio português para além do meridiano de Tordesilhas (a fixar em 1494 os limites dos impérios espanhol e português, e a passar aproximadamente pela longitude das desembocaduras do Amazonas). Se contrapõem constantemente os « fundadores verticais » (criadores das raízes da brasilianidade) no Nordeste aos « fundadores horizontais » (responsáveis pela conquista do território) em São Paulo.

\section{Centralidades}

O universo atlântico representou, nesta fase histórica, o centro do mundo. As colônias do Novo Mundo se qualificam como « Novo Mundo Europeu ». As principais cidades são portos direcionados, principalmente, à Londres, Lisboa e outras cidades européias. No entanto, o Brasil se encontra em posição subalterna face às colônias mais rentáveis da Ásia e participa das trocas no Attântico Sul seja via comércio triangular Portugal-África-Brasil, seja diretamente com Angola, conquistada a partir da colônia.

Os Estados Unidos se constituem como Estado-Nação entre 1765 e 1790. Um dos congressos desse sistema federal em formação designa Washington como capaital federal. Uma das maiores especificidades da civilização americana no final do século XVIII é a desvinculação da cidade política e da cidade econômica, com o intuíto de evitar qualquer forma de concentração. Os Estados Unidos se organizam em torno de três cidades que não tardam em fazer emergir, nos meados do século $\mathrm{XX}$, um continuo urbano a incluir Boston localizado mais ao norte. O geógrafo francês Jean Gottmann a designará de « megalópole americana ».

O geógrafo Donald W. Meinig diferencia, ao longo da fase colonial, a América Espanhola da América Britânica, a primeira ansiando por um império de cidades, diferentemente da segunda, mesmo se elas (particularmente as cidades portuárias) evoluem progressivamente como entidades de poder econômico.

O Brasil é construido na sucessão dos ciclos econômicos (Pau Brasil, cana-de-açucar, ouro, diamantes) cujo controle é exercido, bem ou mal, pela coroa portuguesa, retomando as capitanias em débito e deslocando a capital (de Salvador para o Rio de Janeiro, em 1763) para melhorar recolhimento dos 


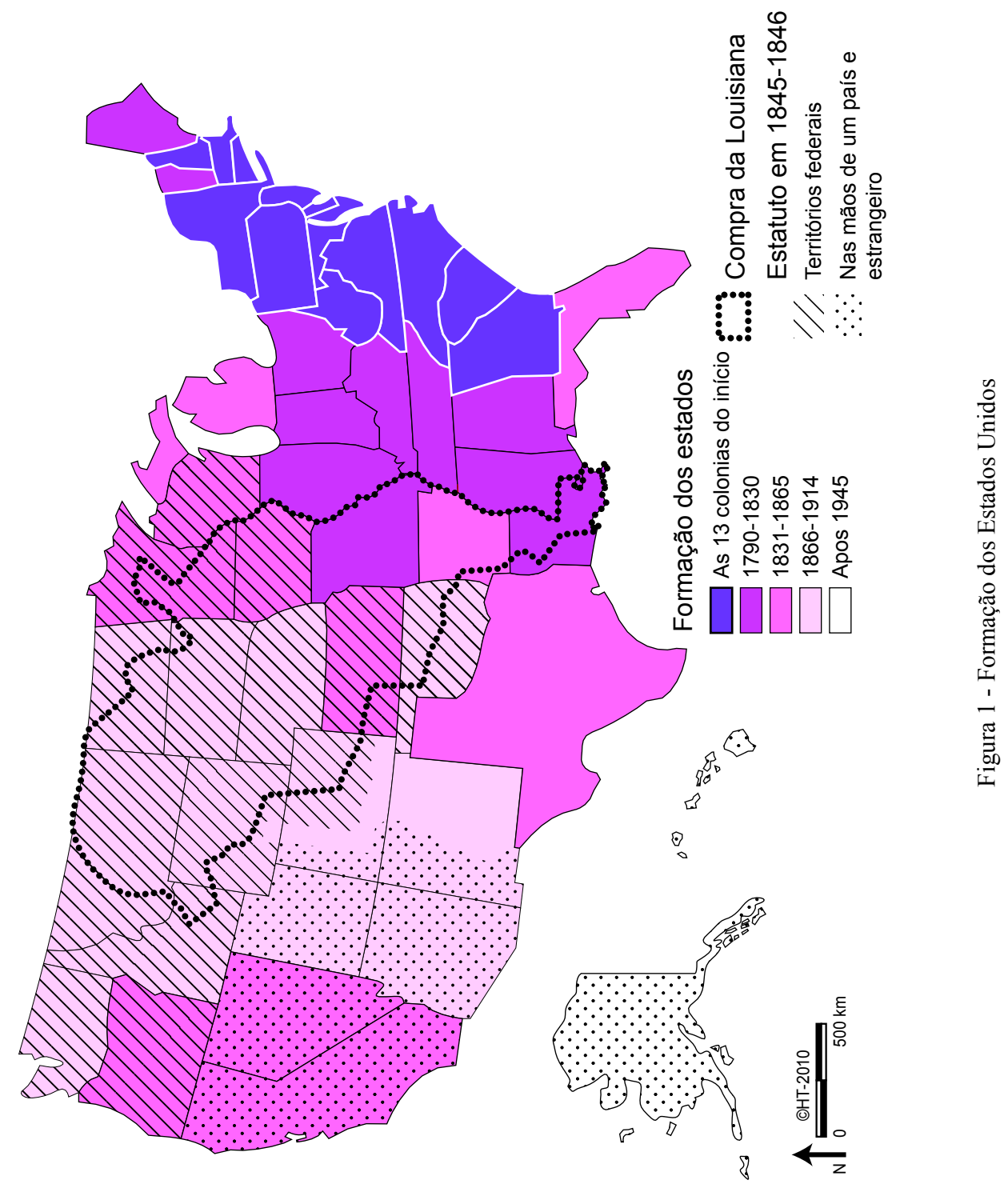

Revista da ANPEGE. v. 6, 2010 (jan./dez.) 
impostos sobre o principal recurso da época. Assegura igualmente a expansão do território com o envio de tropas às fronteiras, a construção de fortes e o controle dos missionários: sua delimitação é quase definitiva no tratado de Madri, em 1750, com alguns retoques na Amazônia, todos favoráveis ao Brasil, no começo do século XX.

Quadro 1 - Fatos históricos no Brasil e Estados Unidos: 1750 a 1789

\begin{tabular}{|c|l|l|}
\hline ANO & \multicolumn{1}{|c|}{ Estados Unidos } & \multicolumn{1}{c|}{ Brasil } \\
\hline 1750 & & $\begin{array}{l}\text { Tratado de Madri, definição do essencial das fronteiras } \\
\text { dos países }\end{array}$ \\
\hline 1763 & A capital é transferida para o Rio de Janeiro \\
\hline 1765 & $\begin{array}{l}\text { Iniciativa de Massachusetts com vista à organização } \\
\text { do primeiro congresso em Nova Yok para responder } \\
\text { ao Stamp Act }\end{array}$ & \\
\hline 1776 & Declaração da independência & $\begin{array}{l}\text { Inconfidência mineira, primeira tentativa (fracassada) de } \\
\text { obtenção de independência }\end{array}$ \\
\hline 1789 & Constituição & \multicolumn{2}{|c|}{} \\
\hline
\end{tabular}

\section{ESTADOS-NAÇÕES SUCEDEM AOS IMPERIOS EUROPEUS}

Esta nova fase histórica pode ser dividida em dois períodos, 1806/1822-1888 et 1888-1960. Para os Estados Unidos, a guerra da secessão marca uma ruptura na medida em que a abolição da escravatura é decisiva no ingresso na fase industrial do capitalismo. Para o Brasil, a primeira fase corresponde ao Império (1822-1889) e, a segunda à República Velha, de 1889 à 1930, até a tomada do poder por Getúlio Vargas, ou até 1960 e a construção de Brasília.

\section{A América continental: 1806/1822-1888}

O século XIX se constitui na fase de consolidação dos Estados-Nações (marcada no contexto estadunidense pela compra da Luisiânia e o desejo de adquirir território estendendo-se até o pacífico) e em período no qual a questão da escravatura toma peso no jogo político. Nos Estados Unidos, a guerra da secessão terminou com a Proclamação da Emancipação de $1^{\circ}$ de Janeiro de 1863 pelo presidente Abraham Lincoln. Dois anos depois, o $13^{\circ}$ código da Constituição aboliu a escravidão.

O século também se caracteriza pela desintegração dos impérios coloniais europeus americanos, sendo os Estados Unidos o maior Estado, com $900.000 \mathrm{Km}^{2}$. Em 1803, Thomas Jefferson negocia com Napoleão Bonaparte a compra da Luisiânia: os Estados Unidos estabelecem a meta de construir o " império da liberdade ». Esta compra permite acesso ao Golfo do México com Nova Orleans e de assegurar a supremacia americana ao longo do rio Mississipe. Em 1845, os Estados Unidos decidem anexar o Texas, origem da guerra com o México. No ano seguinte a Grã Bretanha cede aos Estados Unidos o Oregon, a compor o Canadá britânico e, em 1848, o tratado de Guadalupe Hidalgo finda a guerra entre os Estados Unidos e o México, que aceita lhe ceder vasta parte de seu território, divididos logo em Estados federais : California, Arizona, Nevada, Utah, Novo México e Colorado. Caberá ao Congresso e ao governo federal dotarem-se de ferramentas para delimitar cada um destes Estados a assim permitir-lhes se organizar em condições ideais. 


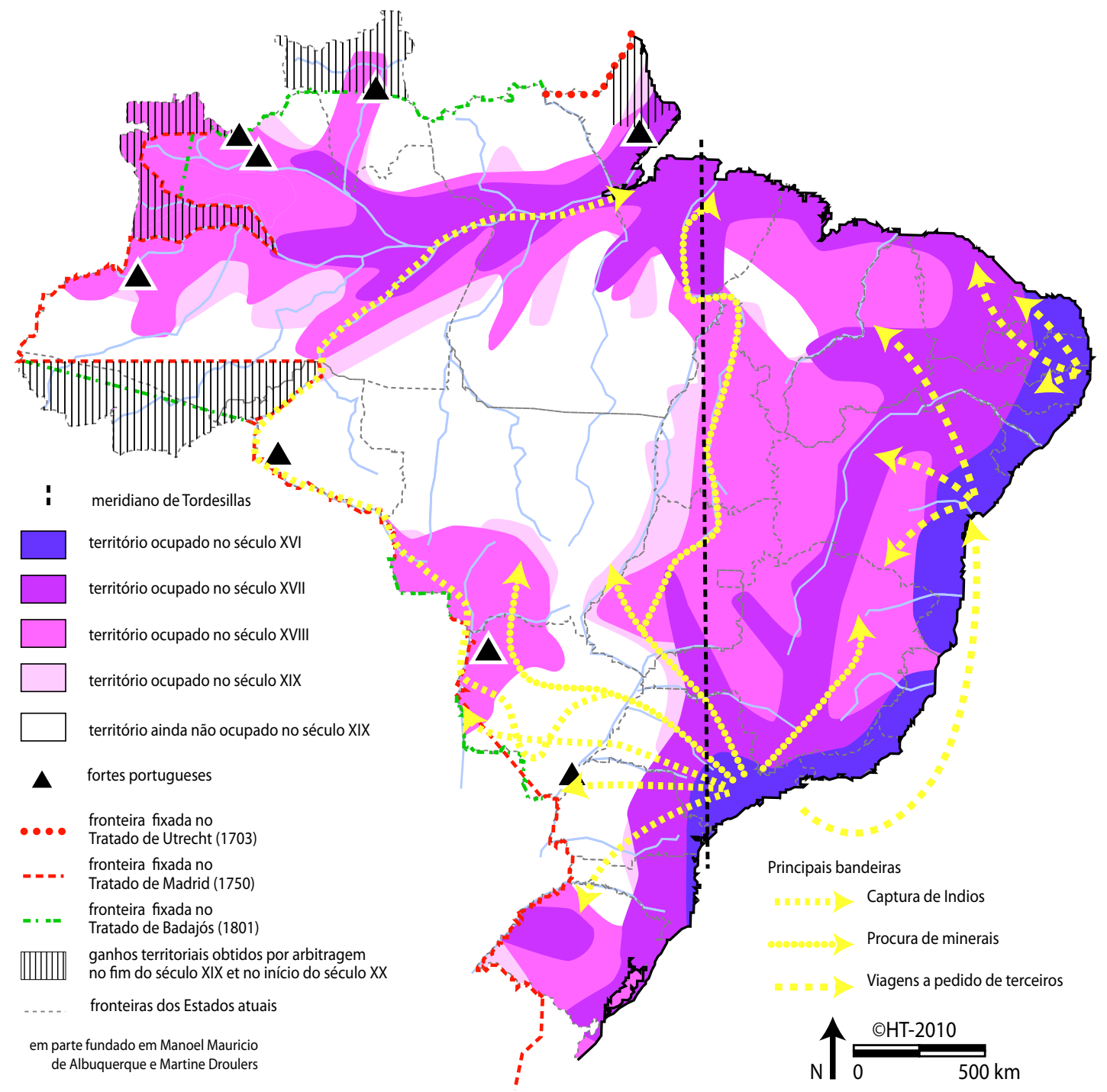

Figura 2 - Brasil, ocupação do território 
Para o Brasil a data chave é 1806, com a transfererência da Coroa portuguesa, ante a ameaça das tropas de Napoleão, para o Rio de Janeiro. Sua presença no Brasil assegura a manutenção da unidade nacional, ao paso que o império espanhol eclode em alguns vinte novos países, em função das inicativas dos burgueses crioulos. Ao findar as hostilidades, o rei retorna a Portugal, deixando seu filho mais novo que, em 1822, decide ficar no Brasil e se proclama imperador, com o nome de Pedro I.

\section{A organização e a administração do território nacional : um jogo técnico e político}

A organização do território (paralelamente à sua extensão espacial) se dá com a criação dos Estados federais, notadamente devido à institucionalização do Corpo de engenheiros topográficos, em 1838. No entanto, a fim de constituir uma nação e de permitir a administração de seu território, o Estado federal (com a figura política de d'Albert Gallatin ) e o Congresso tomaram a decisão de estabelecer uma rede de infraestruturas autorissando notadamente a circulação e a comunicação entre as cidades, tais como estradas, canais e, mais tarde, as estradas de ferro. O canal Erie, que liga o rio Hudson ao lago Erie, construído entre 1819 e 1825 com mais de $500 \mathrm{Km}$ é a figura emblemática deste período. Facilita a circulação das mercadorias reduzindo consideravelmente seus custos e participa do desenvolvimento de uma série de cidades como Búfalo, Rochester, Siracusa, Rome e Utica (no estado de Nova York). Foi após conclusão deste canal que o porto de Nova York se sobrepõs de maneira decisiva sobre os portos da Filadélfia ou de Baltmore: ele também estava tão ligado a portos europeus como a uma parte significativa do território à época. Em 1853, Chicago se intitula « cidade canal ».

O financiamento dessas novas infraestruturas ocorre com conceções fundiárias. Muitos estudos científicos estudaram os diferentes dispositivos disponibilizados pelo governo federal (que nesse início de século XXI ainda é proprietário de um terço de seu território) para permitir às empresas (especialmente as ferroviárias) de decidir o traçado das novas vias e das conexões a estabelecer entre as cidades. O princípio de parceria público-privado é inerente à história de desenvolvimento dos Estados Unidos. A criação de redes de estradas de ferro chamou a atenção de Chevalier em suas Cartas sobre a América do Norte (1837), consagrando ao tema um capítulo inteiro, a tratar da " paixão dos americanos » pelas estradas de ferro. Graças às infraestruturas de transportes, mas também da difusão do telégrafo, a partir dos anos de 1860, a maior parte das grandes cidades criam um sistema de comunicação rápido que lhes assegura o desenvolvimento de um sistema de cidades que, uma vez terminada a guerra de Secessão, se engajam decisivamente na industrialização. O historiador Daniel Boorstin também enfocou o desenvolvimento das mídias, notadamente as diárias como meio de comunicação no seio da cidade, mas também entre as cidades, paralelamente à construção de hotéis à permitir o acolhimento de pessoas provenientes de outras cidades.

Símbolo da constituição progressiva do país, no final do século XIX, o sistema urbano se fortalece, mesmo se tratando de um eixo de relações no sentido leste-oeste: Boston-Buffalo-Milwaukee, BaltimorePittsburgh-St Louis, New York-Cleveland-Chicago.

A organização territorial Brasileira é esencialmente política, o império mantém a unidade através da supressão de várias tentativas de independência de Provincias do Norte e Nordeste, e assegura a respeitabilidade do Brasil no cenário internacional, apesar do estigma da escravatura e da pressão inglesa à favor de sua abolição. Mas a circulação e o controle reais são extremamente precários, restritos ao entorno das principais células produtivas e limitados à cabotagem ao longo da costa e com os mercados externos.

Foi preciso esperar os anos de 1860 para a construção da primeiras ferrovias por empresas britânicas, voltadas à exportação do café via porto de Santos e cidade de São Paulo que principia então seu irresistível crescimento. 
Quadro 2 - Fatos históricos no Brasil e Estados Unidos: 1803 a 1888

\begin{tabular}{|c|c|c|}
\hline ANO & Estados Unidos & Brasil \\
\hline 1803 & Thomas Jefferson negocia a compra da Louisiane & \\
\hline 1806 & & $\begin{array}{l}\text { Chegada do Rei de Portugal e da corte ao Rio de } \\
\text { Janeiro }\end{array}$ \\
\hline 1819 & Aquisição da Flórida & \\
\hline 1822 & & Independência do Império brasileiro \\
\hline 1832 & & Proibição do comércio de escravos \\
\hline 1848 & $\begin{array}{l}\text { Tratado de Guadalupe Hidalgo } \\
\text { O México cede grande extensão do território }\end{array}$ & \\
\hline 1863 & Abraham Lincoln pronuncia a proclamação de emancipação & \\
\hline 1865 & O $13^{\circ}$ artigo da constituição abole a escravidão & \\
\hline 1888 & & Abolição da escravatura e queda do império \\
\hline
\end{tabular}

\section{Centralidades}

No início do século XX, três grands cidades asseguram o essencial da vida econômica: Filadélfia, Nova York e Boston. Com sua hinterlandia respectiva, elas representam um terço da população americana. Esta centralidade partilhada entre três polos explica o espanto de d'Alexis de Tocqueville que escreve, no começo dos anos de 1830, « os Estados Unidos não têm uma grande metrópole ». Mas com o desenvolvimento das infraestruturas incluindo as cidades da costa atlântica às cidades emergentes dos novos territórios, Nova York não tarda a se impor como centro financeiro e centro econômico. Boston mantem sua liderança tanto cultural quanto intelectual, concentrando o maior número de cientistas e de pensadores. No final do século XIX, Chicago começa a se impôr como centro industrial de primeira ordem, após ser destacada no mapa dos Estados Unidos como primeiro hub de estrada de ferro. Durante este período, considerado de primeira globalização moderna (em razão da circulação de capitais e de fluxos migratórios ), ela acolhe, para assegurar a mão-de-obra essencial a seu desenvolvimento, grandes contingentes de imigrantes dos campos europeus.

No Brasil a capital política é o Rio de Janeiro, mas de fato cada província vive sua vida isoladamente, em células agro-exportadoras ou mineradoras ligadas o porto mais próximo e organiza sua própria hinterlândia: Salvador e Recife com o açúcar no Nordeste, Rio de Janeiro e posteriormente São Paulo com o café, mais tarde Belém e Manaus com a borracha da Amazônia.

\section{Os anos 1888-1960}

O final do século XIX, quando a economia é dominada mais pela indústria do que pela agricultura, se apresenta como nova etapa na história dos Estados Unidos : a sociedade inicia inserção na dinâmica do consumo, característica fundamental do « American Way of Life » (Modo de vida Americano) expressa vividamente nos meados do século XX. Os americanos percebem então que seu território se estende do Atlântico até o Pacífico. 


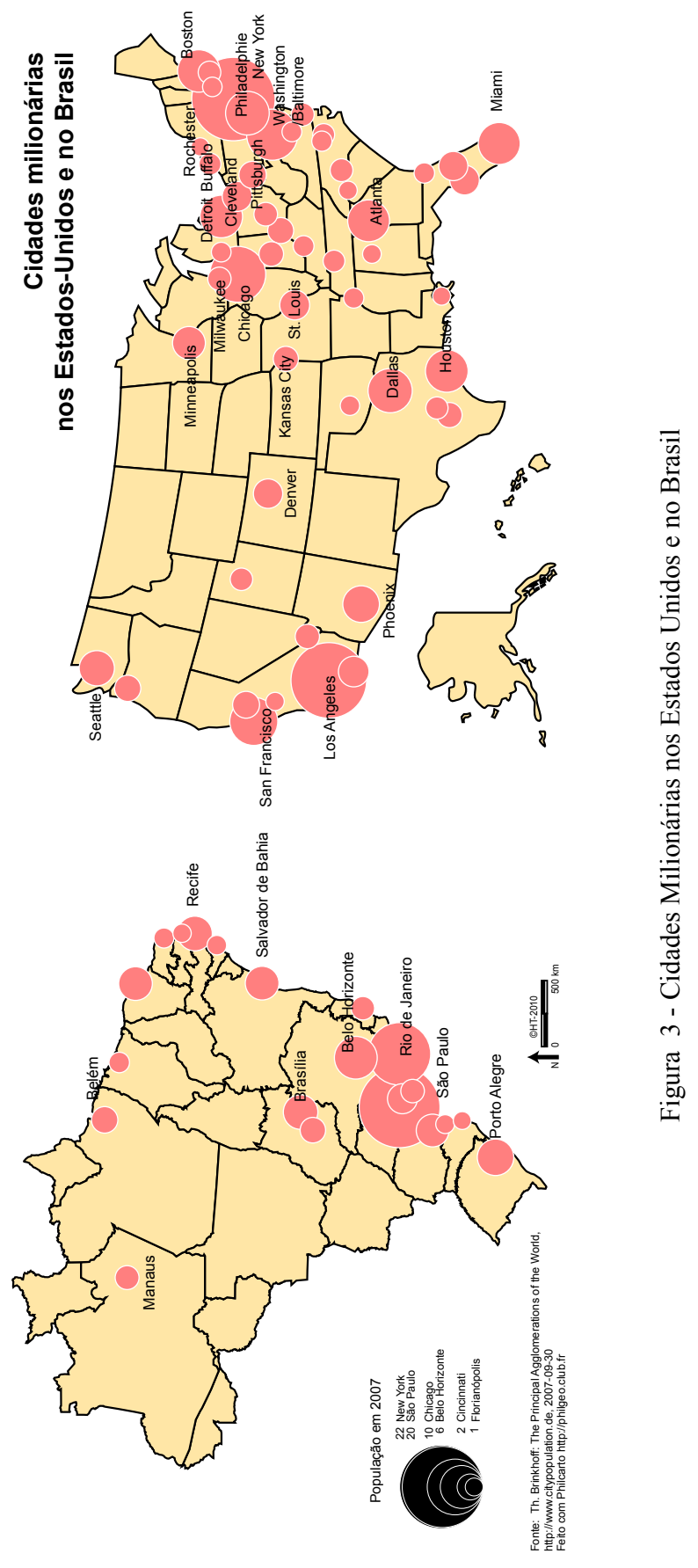

Revista da ANPEGE

GHORRA-GOBIN, C.; THÉRY, H. 


\section{Uma dinâmica inscrita na relação dialética entre sistema de cidades e Estados federais}

No final do século XIX, as Américas se afirmam como povo cuja característica marcante é a da mobilidade, ainda pouco generalizada na Europa (fora os negros, vítimas de segregação). Esta dinâmica explica a intensidade dos fluxos migratórios no território, paralelamente ao aperfeiçoamento do balloom frame (armação de balão), técnica de construção a facilitar desenvolvimento das cidades. A urbanização retoma o mito da fronteira tal qual definido pelo historiador Turner.

No final do século XIX e começo do século XX, as cidads americanas do Centro-Oeste e do Leste se destinguem das cidades da costa devido à sua baixa densidade (ambiente construído), e por um habitat principalmente suburbano.

À véspera da primeira guerra mundial, Nova York afirma sua superioridade no país, principalmente devido sua centralidade incontestável nos fluxos financeiros. Ela não tarda a anexar os cinco municípios vizinhos e se expande sobre vasto território em 1898. Alguns anos mais tarde, o presidente Wilson inaugura nesta mesma cidade o mais alto edifício do mundo: o arranha-céu gótico Woolworth . Londres e Nova York são ligados por telefone após 1884. Chicago é construida em espírito de rivalidade com Nova York.

No Brasil, a representação política repousa na grande propriedade local, monopolizando seu proprietário os poderes locais, o sistema de coronelismo, denominado assim em razão dos potentados locais receberem geralmente o título de coronel da guarda nacional. Com alianças estabelecidas entre eles, mais ou menos instáveis, chegam a controlar a província.

A centralidade econômica é garantida por duas províncias, São Paulo e Minas Gerais, que dividem o poder federal entre si até 1930. Esta época é denominada de «República do café com leite » posto todos os sucessores no poder serem representantes de São Paulo (café) e de Minas Gerais (leite). Após a abolição da escravatura, em 1888, a produção de café é assegurada por imigrantes europeus, principalmente italianos, portugueses e espanhóis que são atraídos pelos barões do café com oferecimento antecipado de recursos para compra de pasagem de navio em troca de contrato para plantar cafezais em suas terras. Embora menor que a emigração para os Estados Unidos e Argentina, este fluxo de europeus para o Brasil contribuiu sensivelmente na modificação da composição e no modo de funcionamento da sociedade, preparando movimentos fundamentais à urbanização, industrialização e democratização, no pós 1930.

Após essa data, a situação muda completamente e assisti-se a uma verdadeira transformação e unificação do país. Sob a direção de Getúlio Vargas (1930-1945) e de seus sucessores. São Paulo tenta, em 1932 uma secessão reprimida à força, posteriormente seus dirigentes, perante o fracasso desta tentativa, optaram pela modernização de seu Estado e decidiram transformá-lo não somente na locomotiva econômica do país, mas também em modelo de modernidade associado a todos domínios, notadamente da cultura e do ensino superior, é o que testemunham a criação da Universidade de São Paulo (1934) e do Museu de Arte Moderna. Neste contexto constroe-se maior parte dos monumentos da cidade, em estilo a se afastar voluntariamente dos modelos ibéricos, inspirando-se primeiro em modelos neoclássicos do norte Europeu (França e Grã Bretanha) posteriormente na arquitetura norte americana, com o surgimento dos primeiros arranha-céus, cujos mais célebres são o edifício Martinelli (nos anos 20) e depois a torre do Banespa (Banco do Estado de São Paulo), inspirado no Empire State Building.

Revista da ANPEGE. v. 6, 2010 (jan./dez.) 
Quadro 3 - Fatos históricos no Brasil e Estados Unidos: 1750 a 1789

\begin{tabular}{|c|c|c|}
\hline ANO & Estados Unidos & Brasil \\
\hline 1889 & & Proclamação da república \\
\hline 1890 & Fim das guerras indígenas com o massacre de Wounded Knee & \\
\hline 1894 & Greve dos ferroviários da Pullman Car Company de Chicago & \\
\hline 1929 & NYSE (NY Stock Exchange) desmorona & \\
\hline 1930 & & Chegada ao poder de Getúlio Vargas \\
\hline 1932 & & Tentativa de secessão em São Paulo \\
\hline 1949 & $\begin{array}{l}\text { A televisão se transforma numa tribuna política com a transmissão } \\
\text { da cerimônia de posse do presidente Truman }\end{array}$ & \\
\hline $1956-60$ & Construção de Brasília & \\
\hline $1958 / 59$ & O Alasca se torna o $49^{\circ}$ estado americano e, o Hawai o $50^{\circ}$ & \\
\hline
\end{tabular}

\section{CONSIDERAÇÕES FINAIS}

Para os Estados Unidos, pode-se concluir enfaticamente o princípio da afirmação de um sistema dual: a dinâmica da sociedade americana ancorada na relação dialética entre sistema de cidades e Estados federais. Este ponto de vista pode ser ilustrado na temática da educação superior, indicador não negligenciável de potência de qualquer Estado preocupado com seu futuro. O ensino superior não se inscreve na hierarquização do sistema urbano (principalmente limitado ao poder econômico) mas o faz sobretudo na disputa entre Estados. No final do século XIX, a Califórnia busca se afirmar face à supremacia dos Estados fundadores como Massachussetts (e não São Francisco ou sua periferia face à Boston e Canbridge), criando em 1868 sua primeira universidade pública, UC Berkeley e, em 1919, o campus de Los Angeles. $\mathrm{O}$ «UC system» ou ainda a rede de universidades públicas californianas corresponde hoje a dez campus gerenciados por um comité (Board of Regents) independente do Estado. A iniciativa do Estado californiano foi seguida pela do Senhor e Senhora Stanford a financiarem em 1885 uma universidade privada com o nome da família, em memória de filho mais velho morto de tifo durante viagem à Europa.

No Brasil, se adotarmos o mesmo critério, pode-se contrapor as universidasdes federais às do Estado de São Paulo, principalmente UNICAMP (Campinas) e, sobretudo, USP (Universidade de São Paulo), a mais prestigiosa universidade do país, a única classificada entre as 200 do mundo pelo Instituto de Educação Superior de Shangai, Universidade de Jiao Tong. O recente desenvolvimento de novas universidades privadas (após os anos de 1990) não põem em dúvida esta dominação, pois intentam principalmente oferecer diplomas a candidatos vindos das classes populares, que até então não tinham acesso ao ensino superior, e sem ambição no domínio da pesquisa e da formação de pósgraduandos. 
A análise comparativa da organização territorial sublinha, tanto no Brasil com nos Estados Unidos, a dualidade de uma dinâmica baseada no princípio federal e no sistema de cidades. Nos Estados Unidos os atores da construção do território proveem tanto do setor privado quanto do público e, juntos, trabalham na construção de quadro capaz de impedir que os estados costeiros não levem vantagens em relaçao aos mais recentes, incluindo aqueles localizados no Pacífico. No Brasil o papel do Estado federal por muito tempo foi limitadissímo, predominando durante os regimes autoritários, mas a ascenção do setor privado, com base principalmente em São Paulo, se deu de tal maneira que mostrou necessário compor e permitir desenvolvimento de um sistema mais policêntrico.

Além de suas diferenças, a análise comparativa permite salientar os limites de representação da dinâmica territorial somente baseada no sistema urbano. Permite enfatizar a hipótese da sustentabilidade do modelo nacional na era da globalização econômica (fundada a priori nos fluxos transnacionais), desde que se tenha uma coordenação eficaz entre os atores territoriais (setor privado, setor público e sociedade civil).

\section{REFERÊNCIAS BIBLIOGRÁFICAS}

BOORSTIN, D. J.THE AMERICANS. New York: Random House, 1965.

BUARQUE DE HOLANDA, S. Raízes do Brasil. Rio de Janeiro: José Olimpio, 1936.

CONZEN, M. P. A transportation Interpretation of the Growth of Urban Regions: An American Example. Journal of Historical Geography 1, octobre 1975, p. 361-82.

CONZEN, M. P. The maturing Urban System in the United States, 1840-1910. Annals of the Association of American Geographers 67 (mars 1977). p. 88-108.

FURTADO, C. La Formation Économique du Brésil de l’époque coloniale aux temps modernes. Paris : Mouton, 1973.

GHORRA-GOBIN, C. Les Américains et leur territoire. Mythes et réalités. Paris: Documentation Française, 1987

GHORRA-GOBIN, C. La frontière : espace de formation de l'identité nationale ? Hérodote $\mathrm{N}^{\circ} 72-73$, Janvier-Juin 1994. p. 170-180.

GHORRA-GOBIN, C. Villes et Société Urbaine aux États-Unis. Paris: Colin, 2003.

GLAAB, Ch. N.; BROWN, Th. A History of Urban America. New York: Macmillan, 1967.

MEINIG, D. W. The Shaping of America: A Geographical Perspective on 500 Years of History. Yale University press, 1986, 1993, 1998.

MUSSET, A. Villes nomades du Nouveau Monde. Paris: Éditions de l’EHESS, 2002.

PRED, A. R. The Spatial Dynamics of US Urban-Industrial Growth 1800-1914: Interpretive and Thoeretical Essays. MIT press, 1966.

STILGOE, J.R. Metropolitan Corridor: Railroads \& the American Scene. New Haven: Yale University press, 1983.

THÉRY, H. Le Brésil. Paris: Armand Colin, 2005.

THÉRY, H.; MELLO, N. A. Atlas du Brésil, Paris: La Documentation Française, 2003.

TURNER, F. J. Frontier and Section: Selected Essays of Frederick Jackson. Prentice-Hall, 1961.

Revista da ANPEGE. v. 6, 2010 (jan./dez.) 
VANCE, J. E. Capturing the Horizon: The Historical Geography of Transportation since the Transportation Revolution of the Sixteen Century, New York, Harper Row, 1986.

Recebido em abril de 2010 Aceito em dezembro de 2010 